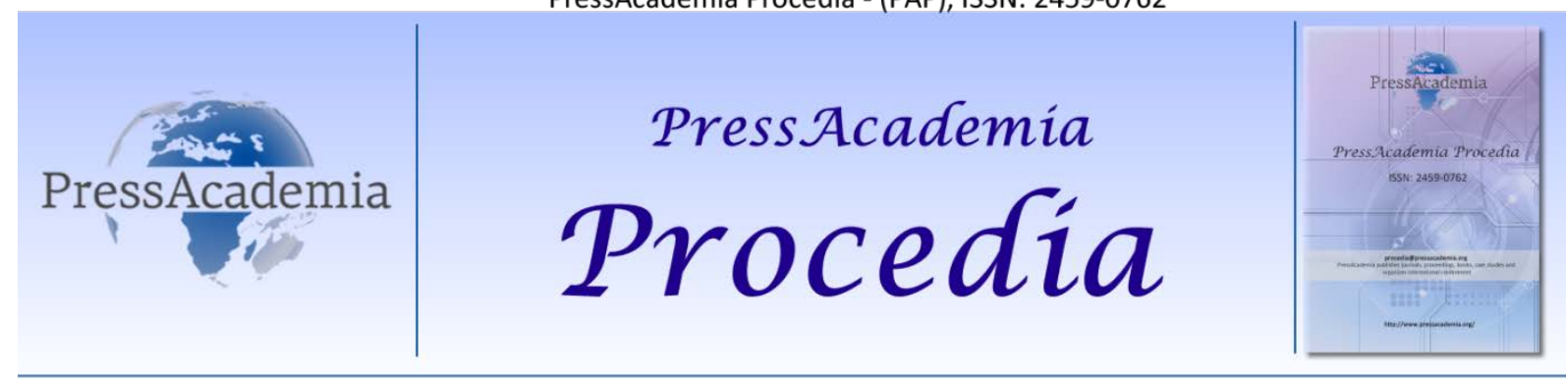

Global Business Research Congress (GBRC), June 4-5, 2015, Istanbul, Turkey.

\title{
ERGONOMICS RISK ANALYSIS IN AUTOMOBILE CABLE MANUFACTURING
}

\section{DOI: 10.17261/Pressacademia.2016118137}

\section{Ilker Bogac Ulutas ${ }^{1}$, Tulin Gunduz ${ }^{2}$}

Işık University. ilker.ulutas@isikun.edu.tr

Uludağ Üniversitesi. tg@uludag.edu.tr

\begin{abstract}
Musculoskeletal diseases are one of the most important issues among occupationFal health illnesses because the workforce, not only developing but also developed countries are affected and burdens social security systems with high financial costs, further decreases qualified emloyees. This study analysis the musculoskeletal diseases in a cable manufacturing facility and provides new applications to eliminate physical risk factos. Based on video records, Quick Exposure Check (QEC) are made for ergonomic risk analysis and required arrangements are suggested for the related departments. Then, results are assesed in terms of efficiency. Finally, it was seen that ergonomics analysis have decreased musculoskeletal disease risks.
\end{abstract}

Keywords: health management, ergonomics risk analysis, musculoskeletal diseases, quick exposure check JEL Codes: I10, L62

\section{OTOMOTIV KABLO ÜRETMINDE ERGONOMIK RISK ANALIZI}

\section{ÖZET}

Meslek hastalıkları arasında özellikle Kas İskelet Sistemi Hastalıklarının (KiSH), hem gelişmiş hem de gelişmekte olan ülkelerde dikkat çekici bir artış göstermesi, işletmelere ve dolayısıyla sosyal güvenlik sistemlerine ciddi finansal yükler getirmekte ve nitelikli insan gücünü azaltmaktadır. Bu çalışmada, kablo imalatı yapılan bir fabrikada KiSH ile ilişkili problemler tespit edilmiş ve fiziksel risk etmenlerinin iyileştirilmesi için yeni uygulamalar geliştirilmiştir. Üretim alanında video çekimleri yapılmış, bunun üzerinden Hızlı Maruziyet Değerlendirme (HMD) Yöntemi kullanılarak ergonomik risk analiz metotları uygulanmış, ilgili bölümler için gerekli düzenlemeler önerilmiştir. Bu düzenlemeler sonrası tekrar analiz yapılarak elde edilen sonuçların etkinliği değerlendirilmiştir. Yapılan ergonomi analizleri ile KiSH riski azaltılmıştır.

Anahtar kelimeler: Sağlık yönetimi, rrgonomik risk analizi, HMD JEL Kodları: I10, L62 


\section{GiRiş}

İşe bağlı Kas İskelet Sistemi Hastalıkları (KiSH) fiziksel çaba ile ilişkili olup, dünyanın her tarafında en yaygın sağlık problemlerinden biridir. KiSH, kasların, sinirlerin, bağ dokuların, tendonların, eklemlerin, kıkırdakların ve spinal diskin yaralanması ve bozuklukları olarak tanımlanır. Kayma, düşme veya benzeri kazalardan kaynaklanan yaralanmaları içermez. İngiltere'de, sağılk ve güvenlik iradesi (Health and Safety Executive-HSE) ve Washington state çalışma ve endüstri departmanı (Washington State Department of Labour and Industries) raporlarında (Safety Health Assesment and Research for Prevention, SHARP-2005), endüstride çalışanların \%50 den fazlasının KiSH çektiği bildirilmiştir. Meslek hastalıkları arasında özellikle KiSH, hem gelişmiş hem de gelişmekte olan ülkelerde dikkat çekici bir artış göstermesi, işletmelere ve dolayısıyla sosyal güvenlik sistemlerine ciddi finansal yükler getirmekte ve nitelikli insan gücünü azaltmaktadır.

Sanayileşmeye bağlı olarak çalışanların maruz kaldıkları iş kazası ve meslek hastalıklarında artışlar olmasıyla birlikte yeni tehlike ve risk grupları ortaya çıkmaktadır. Çok fazla önem verilmeyen bu sorunlar işletmenin güvenli bir şekilde çalışması önlemektedir. Hem şirket açısından hem de çalışan açısından değerlendirildiğinde, maddi ve manevi kayıplar oluşmaktadır. Uluslararası Çalışma Örgütün'e göre (International Labour Office, 2007); dünyada, ortalama 270 milyon iş kazası olmakta ve 200.000 kişi hayatını kaybetmektedir.

Bu çalışmada, bir otomotiv kablo imalatı yapılan bir firmada Kas - İskelet Sistemi Hastalıkları (KiSH) ile ilişkili problemler tespit edilmiş ve çalışanlar için ergonomik risklerin etkisini azaltmak üzere çalışma gerçekleştirilmiştir.

\section{METOT}

Bu çalışmada, işe bağlı KiSH ile ilgili maruziyet değerlendirmede yaygın olarak kullanılan Hızlı Maruziyet Değerlendirme (HMD) metodu uygulanmıştır.

Hızlı Maruziyet Değerlendirme (HMD), 1998 de Li ve Buckle tarafından geliştirilmiş ve 2003 te David, Woods ve Buckle tarafından yeniden gözden geçirilerek iyileştirilmiştir. Çalışmalar, HMD’nin gözlemciler arası ve gözlemci içi güvenirliğe sahip olduğunu da göstermiştir. HMD’nin önemli özelliklerinden biri de değerlendirme sürecinde çalışanın da katılımının sağlanmasıdır. İki bölümden oluşan ölçeğin, gözlemciye ait bölümünde çalışma esnasında bel, omuz/kol, el bileği/el ve boyunda postür ve hareketleri değerlendiren 18 madde bulunur. HMD, Ingiltere, Kanada, Kore, İran gibi pek çok ülkede, çalışmalarda ve günlük pratik uygulamalarda kullanılmaktadır. Kanada ve Ingiltere'de HMD yöntemine dayandırılarak kas iskelet hastalıkları için risk değerlendirme rehberi hazırlanmıştır (Özcan E, 2011). HMD metodunun uygulama esasları ile ilgili detayları Ek 1'de verilmiştir.

\section{UYGULAMA}

Otomotiv kablo montajı yapılan firmanın yıl için verileri incelendiğinde KiSH' nda diğer hastalıklara oranla önemli düzeyde bir artış olduğu belirlenmiştir. Bunun üzerine, operatörden alınan geri bildirimlerden hareketle, her 3 vardiyada video çekimleri yapılmış, mandal masalarının bulunduğu alanlara yoğunlaşımıştır. Bu bölümlerde çalışanların yaşadığı sıkıntılar ve öneriler kayıt altına alınmıştır. Fabrikada operatörlerin yaşadığı problemler şu şekilde belirlenmiştir:

Operatörlerin L-Form Mandal Masalarında zaman zaman birbirleriyle çarpıştıkları, çok eğildikleri ve bazı modüllerin yönünden dolayı kabloları tutan agrafları keserken zorlandıkları ve bunlara bağlı bel ve el bileği ağrıları yaşadıkları görülmüştür (Şekil 1). L-Form Mandal masası iş çakışması Şekil 2'de görüldüğü gibi oluşmaktadır. 
Şekil 1: L-Form Mandal Masası iş çakışması ve masaya uzanımları
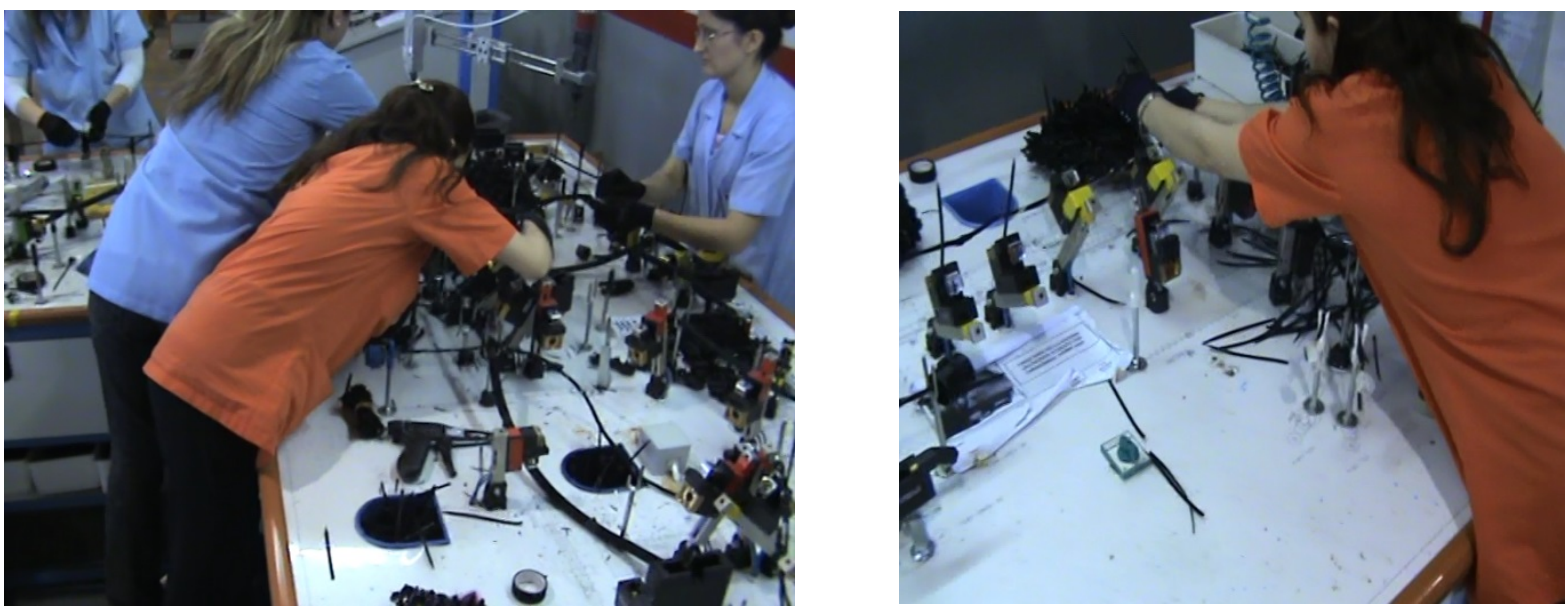

Şekil 2: L-Form Mandal masası iş çakışması şematik gösterimi

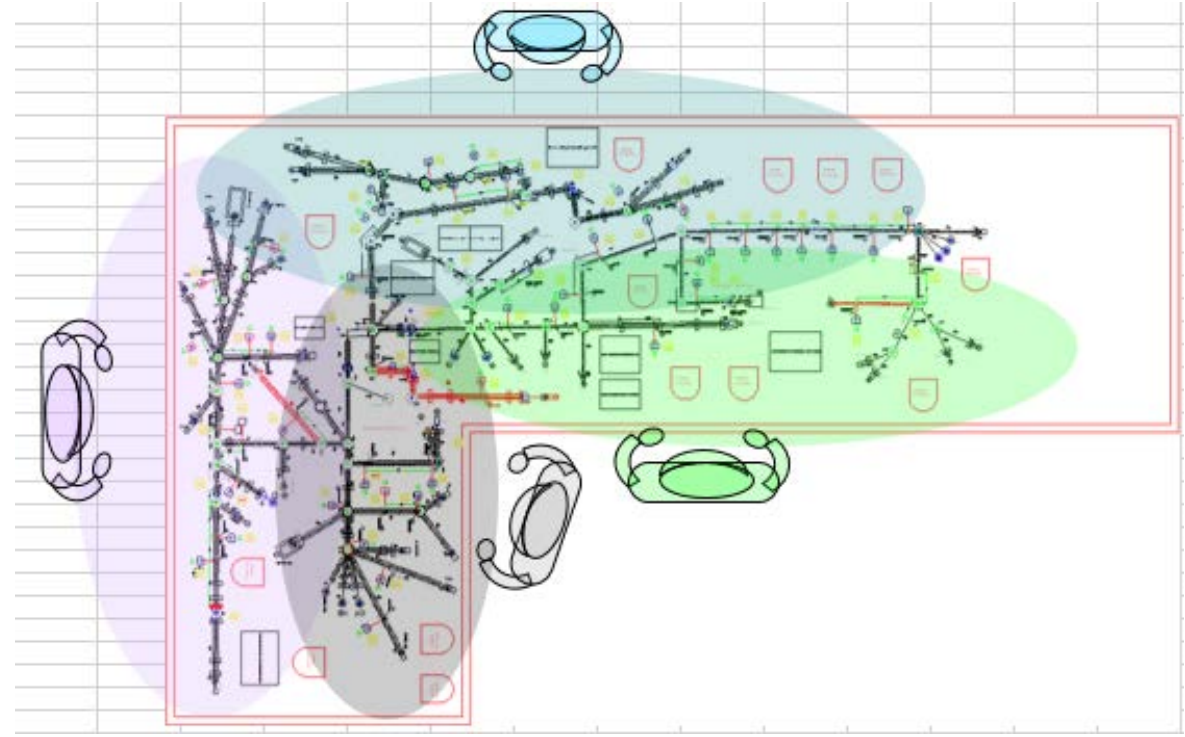

L-Form mandal masaları bölümde de HMD yöntemi sonucu, bel bölgesinin çok yüksek, boyun bölgesinin yüksek, omuz/kol, bilek/kol bölümlerininde yükseğe çok yakın olduğu görülmüştür (Şekil 3). İş temposu yüksek, stresinde yine 18 gibi çok yüksek değerinin de üzerine çıktığı tespit edilmiştir. 
Şekil 3: L-Form Mandal Masaları: HMD Yöntemi

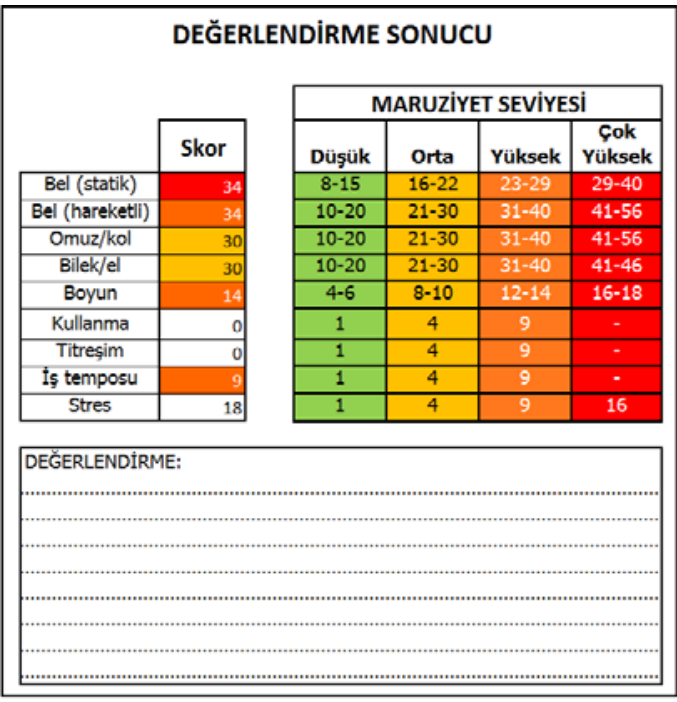

Yapılan analizler sonucunda;

a. Köşeli mandal masalarının iş çakışmalarına neden olduğu için kullanımının terk edilmesi gerekliliği,

b. Çalışma sırasında operatörler mandal masalarına çok eğilmek zorunda kaldıkları için iş dağılımlarının mesafeye göre ayarlanması gerektiği,

c. Masadaki modüllerde yön değişikliği yapılarak agraf kesimlerinin daha kolay hale getirilmesi ve modüllerin konulacağı yerlerin iş çakışmasına sebep olmadan yapılması ve bundan sonraki dizayn ve yerleşim planı hazırlanırken tüm bunların göz önünde bulundurulması gerekliliği ortaya çıkarılmıştır.

Bu önerilerin ışığında gerekli aksiyonlar tartışılıp, ilgili bölümler tarafından termin tarihleri belirlenerek tutanak altına alınmıştır. Yapılan çalışmalar sonrası mandal masaları için yeni bir dizayn oluşturulmuştur ve Şekil $4^{\prime}$ de gösterildiği gibi uygulamaya alınmıştır.

Şekil 4: Yeni Dizayn mandal masası operatör yerleşimleri
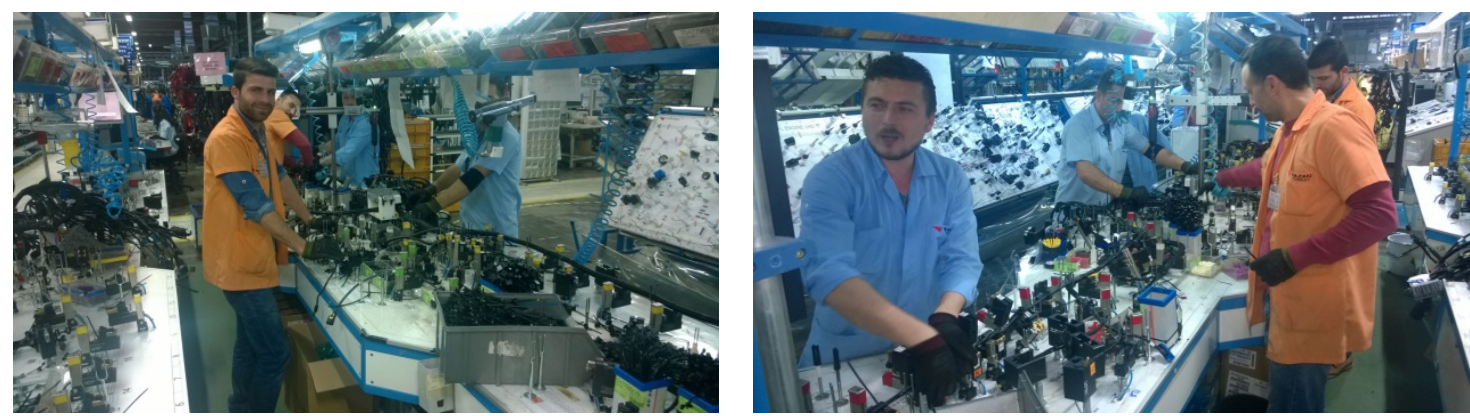

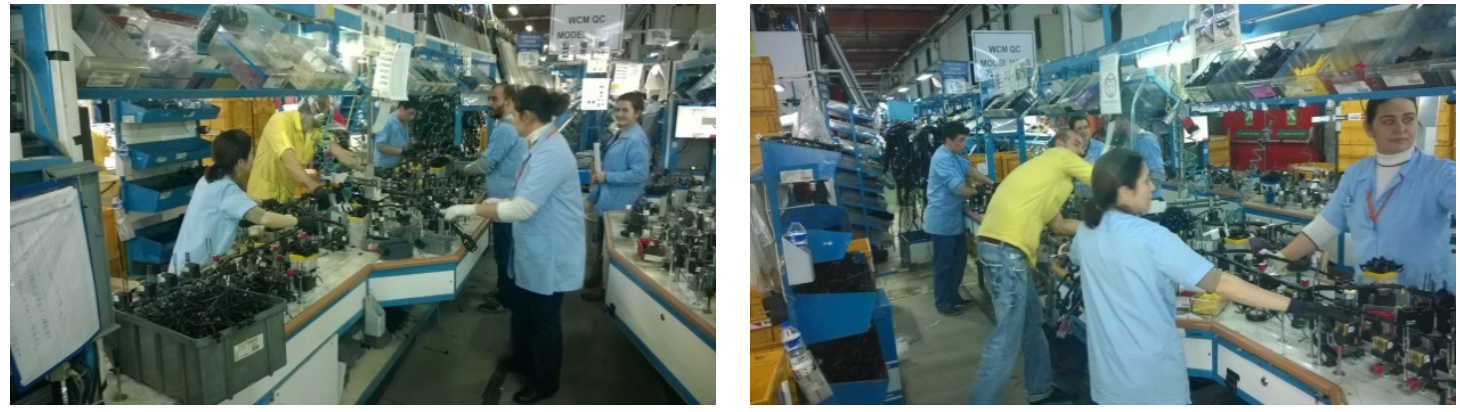

Yapılan yeni mandal masası sonrası HMD analizi tekrarlandığında ortaya çıkan sonuç Şekil 5'de görülmektedir. Değerlendirme sonucu bel el bileği boyun bölgelerinde görülen iyileşme sonuçları ile iş temposu ve stres seviyesindeki düşmeler anlamlı kabul edilmiştir.

Şekil 5: İyileştirme sonrası mandal masalarında yapılan HMD yöntemi uygulaması

\section{DEĞERLENDIRME SONUCU}

\begin{tabular}{|c|c|c|c|c|c|}
\hline & \multirow[b]{2}{*}{ Skor } & \multicolumn{4}{|c|}{ MARUZIYET SEVIYESI } \\
\hline & & Düşük & Orta & Yüksek & $\begin{array}{c}\text { Çok } \\
\text { Yüksek }\end{array}$ \\
\hline Bel (statik) & 26 & $8-15$ & $16-22$ & $23-29$ & $29-40$ \\
\hline Bel (hareketli) & 26 & $10-20$ & $21-30$ & $\overline{31-40}$ & $41-56$ \\
\hline Omuz/kol & 30 & $10-20$ & $21-30$ & $\overline{31-40}$ & $41-56$ \\
\hline Bilek/el & 26 & $10-20$ & $21-30$ & $31-40$ & $41-46$ \\
\hline Boyun & 12 & $4-6$ & $8-10$ & $\overline{12-14}$ & $16-18$ \\
\hline Kullanma & 0 & 1 & 4 & 9 & - \\
\hline Titreşim & 0 & 1 & 4 & 9 & - \\
\hline İş temposu & 4 & 1 & 4 & $\overline{9}$ & - \\
\hline Stres & 4 & 1 & 4 & $\overline{9}$ & 16 \\
\hline
\end{tabular}
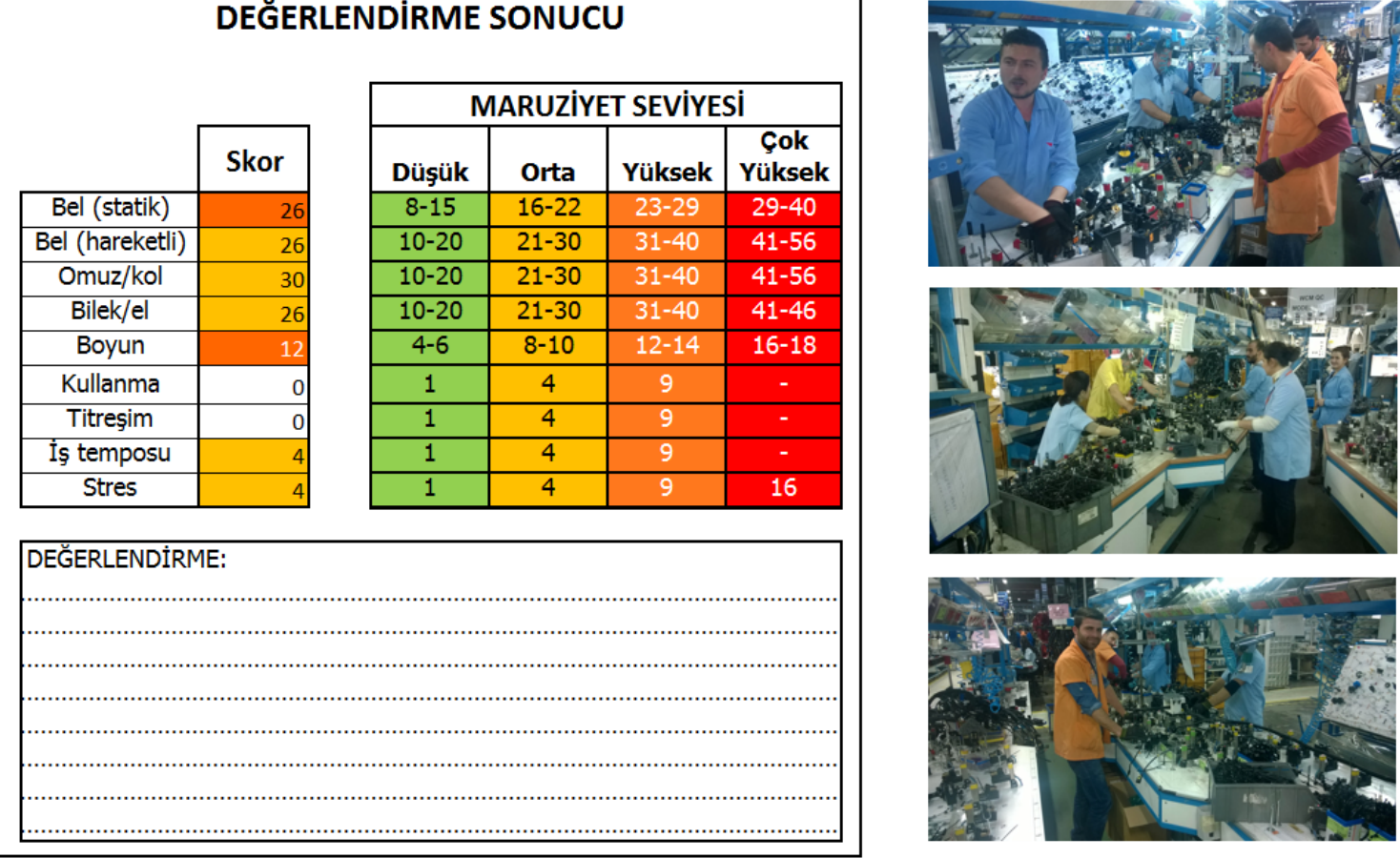

\section{SONUÇ}

İ̧ Sağlığı ve Güvenliği pratiğinde saha gözlemi son derece önemlidir. Saha gözlemi, üretim için yapılan kontroller, öneri sistemleri, operatörlerden alınan geri bildirimler ve sağlık istatistikleri ile yapılmaktadır. Otomotiv kablo imalatı yapılan firmada mandal masaları önemli düzeyde risk oluşturabilecek kas iskelet sistemi hastalıkları oluşabilmektedir. Ortaya çıkan problemlere yönelik yeni hat tasarımı gerçekleştirilmiş ve uygulamaya alınmıştır. Oluşan yeni durumda yapılan HMD analizleri sonucunda, mesleki kas iskelet sistemi hastalıklarına risk oluşturabilecek faktörlerin anlamlı düzeyde azaldığı görülmüştür. 


\section{KAYNAKLAR}

http://www.ilo.org/global/lang--en/index.htm .

http://www.sgk.gov.tr/

http://www.csgb.gov.tr

David G, Woods V, Buckle P. Further development of the usability and validity of the Quick Exposure Check (QEC) HSE Books, ISBN 07176 $28256,68,2005$

Li, G. ve Buckle, P. 1999. Current techniques for assessing physical exposure to workrelated musculoskeletal risks, with emphasis on posture-based methods. Ergonomics, 42(5), 674-695.

Özcan E, 2011. İş yerinde ergonomik risklerin değerlendirilmesi ve Hızlı Maruziyet Değerlendirme Yöntemi (HMD), Mühendis ve Makine, 52(616), 86-89. 
Ek 1. Hızlı maruziyet değerlendirme formu

HIZU MARUZIYET DEĞERLENDIRME FORMU

\begin{tabular}{|c|c|}
\hline Calponin Adysid: & Deferiendimey| Yortan: \\
\hline 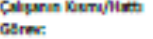 & Tarh: \\
\hline
\end{tabular}

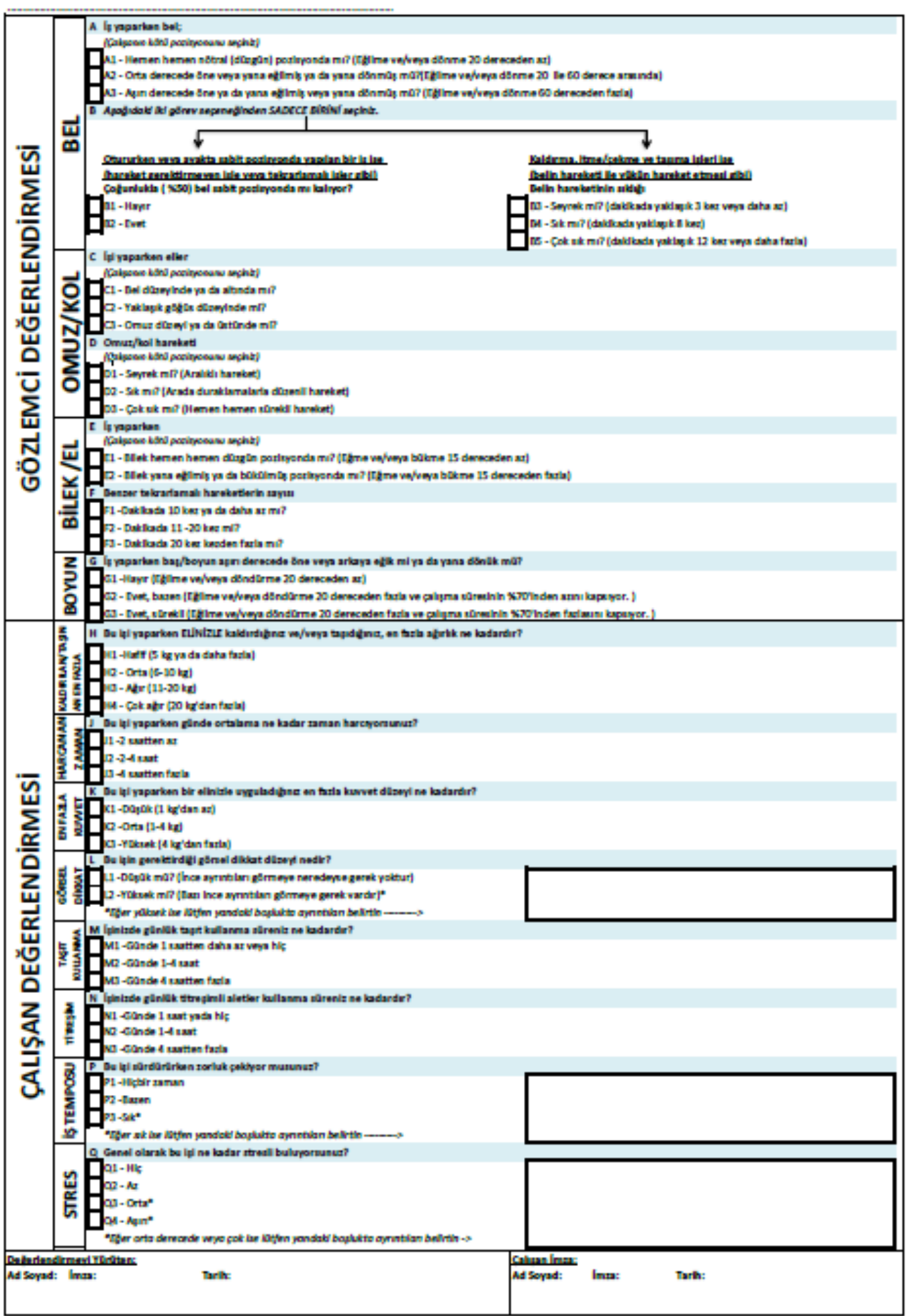

